\title{
MicroRNAs in diagnosis and prognosis in cancer: what does the future hold?
}

\section{"In cancer, miRNAs have the capacity to target a multitude of biological processes, such as proliferation and angiogenesis, that are critical to tumor growth and progression."}

MicroRNAs (miRNA) were first identified in 1993 as small, endogenous, approximately 22 nucleotide noncoding RNAs that had the capacity for gene regulation in larval development [1]. Since this initial discovery, miRNAs have emerged as regulators of essential biological functions, including cellular development, apoptosis and metabolism. It is estimated that miRNAs may regulate up to a third of the human genome. MiRNAs are often located in fragile regions of the chromosome that are susceptible to deletions, rearrangements and amplification, and as a result have been primarily implicated in malignancy [2]. In 2002, Calin et al. first demonstrated that miR-15a and miR$16-1$, located in the fragile chromosomal region 13q14, were frequently decreased in expression in patients with chronic lymphocytic leukemia [3]. Upon further evaluation, they determined that both miRNAs are likely to function as tumor suppressors in chronic lymphocytic leukemia and were linked to an indolent form of the disease. MiRNAs may function either directly as tumor suppressors or oncogenes, or indirectly by globally altering methylation [4]. In addition, miRNA are currently being investigated as diagnostic and prognostic biomarkers of disease. In the last several years, investigators have identified their functional role in cardiac, endocrine and rheumatological disease, as well as both the innate and adaptive immune response. To date, the majority of miRNA studies have been conducted in both in vitro cell systems and in murine models, each of which have limitations. For example, while miRNAs may alter cellular phenotype, such approaches may not replicate tumor/microenvironment conditions, physiological levels of miRNA expression or offtarget effects. Nevertheless, such studies have been integral to translating miRNA biology to eventual clinical application. The miRNA field is moving rapidly. What does the future hold?
Studies have demonstrated that miRNAs may be specific to or enriched for tissue and disease types. For example, miR-122 is liver specific while miR-126 in enriched in the vasculature $[5,6]$. There are several high-throughput approaches to quantifying miRNAs in tissue samples, but the gold standard is still unclear. Northern blotting was initially one of the primary methods used to detect individual small RNAs. cDNA oligonucleotide arrays have become a standard global-scale technique for miRNA profiling [7]. Real-time PCR has been successfully used for detecting low copy number precursor and mature miRNA with high sensitivity and specificity $[8]$. Deep sequencing is also being used to identify both miRNAs and other noncoding RNAs [9].

\section{"Novel modalities of delivery, including systemic administration of miRNA are beginning to emerge."}

In cancer, miRNAs have the capacity to target a multitude of biological processes, such as proliferation and angiogenesis, that are critical to tumor growth and progression. MiR-21, for example, functionally targets tumor suppressors to promote tumor progression [10]. Increased expression of miR-21 has been linked to several solid tumors, including breast, lung, prostate and gliomas [11-13]. MiR-9 is important to tumor metastases through regulation of E-cadherin, which is involved in epithelialmesenchymal transition [14]. The let-7 family is perhaps one of the best studied miRNA in malignancies. Let-7 functionally targets $K R A S$, $M Y C$ and $H M G A 2$ to inhibit tumor growth and progression $[15,16]$. Let-7 expression has also been associated with clinical outcome in solid tumors, most notably lung cancer. MiRNAs may also be utilized as biomarkers of prognosis in disease. For example, in patients with stage 1

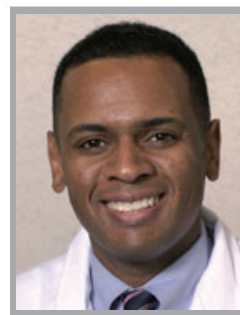

Patrick Nana-Sinkam

Author for correspondence: Division of Pulmonary, Allergy, Critical Care \& Sleep Medicine, Ohio State University Medical Center, Davis HLR , 473 W 12th Avenue, Room 201, Columbus, OH 43210, USA

Tel.: +1 6142477707

Fax: +16142934799

Patrick.Nana-Sinkam@osumc.edu

and

James Comprehensive Cancer Center, Columbus, OH 43210, USA

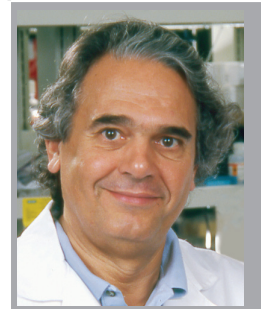

Carlo M Croce

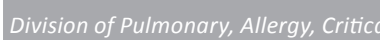
Care \& Sleep Medicine, Ohio State University Medical Center, $\mathrm{OH}$, USA and Molecular Virology, Immunology \& Medical Genetics, Ohio State University Medical Center, $\mathrm{OH}$, USA 
non-small-cell cancer of the lung, increased miR-155 and decreased let-7a correlated with a poor outcome [17]. A more recent study in a cohort identified a five-miRNA signature ( $\mathrm{miR}$ 25, miR-191, let-7e, miR-34c-5p and miR-34a) that correlated with survival in patients with squamous cell carcinoma of the lung [18]. MiRNA signatures have also been correlated with survival in liver cancer, cervical cancer and diffuse B-cell lymphoma [19-21].

\section{"As investigators continue to study circulating miRNA, they will need to determine whether serum, plasma or peripheral blood mononuclear cells harbor the ideal signature, and which is the most accurate platform for miRNA detection."}

The prospect of successful in vivo targeting and regulation of miRNA is exciting. In vitro strategies include mimics for gain of function and the silencing of select miRNA. The majority of studies have utilized elegant transgenic murine models that are an important first step to therapeutic development. Developing miRNA delivery for clinical application is the next logical step. However, optimal modes of miRNA delivery and targeting and the potential for offtarget effects in vivo still need to be addressed. Novel modalities of delivery, including systemic administration of miRNA are beginning to emerge. The liver-enriched miRNA, miR-122, has received a great deal of attention as a potential therapeutic target. In vivo studies in both mice and primates show that the systemic administration of antisense miR-122 could be used to alter lipid metabolism and hepatitis $\mathrm{C}$ viral load [22]. Very few similar studies exist in cancer, however, Kota et al. demonstrated that systemic delivery of miR-26 in a murine model of hepatocellular carcinoma could reduce liver tumor size [23].

"One should consider that miRNAs represent
only one of a family of noncoding RNAs,
many of which have yet to be fully studied as
regulators of gene and protein expression."

Noninvasive modalities for cancer detection and surveillance remain in high demand for the majority of solid malignancies. Circulating miRNAs have been identified in serum, in plasma and packaged in microvesicles [24]. Mitchell et al. recently determined that circulating miRNAs are present in a stable form in the serum [25]. Furthermore, miRNA could distinguish patients with and without prostate cancer. Similar studies have been conducted in B-cell lymphoma, colorectal cancer and ovarian cancer $[21,26,27]$. Whether changes in circulating miRNA are primarily tumor driven or represent a systemic response is unclear. As investigators continue to study circulating miRNA, they will need to determine whether serum, plasma or peripheral blood mononuclear cells harbor the ideal signature, and which is the most accurate platform for miRNA detection.

\section{"...there are likely to be several other layers to miRNA regulation, such as functional miRNA genetic variants and target sequence polymorphisms that compromise miRNA binding and regulation."}

As the number of known miRNAs in the human genome rapidly approaches 1000 , we have only begun to understand the role that miRNA plays in the pathogenesis of human disease. One should consider that miRNAs represent only one of a family of noncoding RNAs, many of which have yet to be fully studied as regulators of gene and protein expression [28]. In addition, there are likely to be several other layers to miRNA regulation, such as functional miRNA genetic variants and target sequence polymorphisms that compromise miRNA binding and regulation [29]. Chin et al. showed that a SNP in the KRAS 3'-UTR was associated with an increased risk of lung cancer with an odds ratio of 2.3 [30]. In the era of 'personalized medicine' it will be important to identify novel platforms that can be applied to clarify disease risk assessment, disease heterogeneity, therapeutic response and targets. Given their capacity for targeting hundreds of genes simultaneously, and thus biological networks, miRNAs are particularly attractive candidates. As miRNAs transition to clinical application they may be utilized as diagnostic or therapeutic biomarkers, to complement current treatment modalities or as direct therapies. The future is bright indeed.

\section{Financial \& competing interests disclosure}

The authors have no relevant affiliations or financial involvement with any organization or entity with a financial interest in or financial conflict with the subject matter or materials discussed in the manuscript. This includes employment, consultancies, honoraria, stock ownership or options, expert testimony, grants or patents received or pending, or royalties.

No writing assistance was utilized in the production of this manuscript. 


\section{Bibliography}

1 Lee RC, Feinbaum RL, Ambros V: The C. elegans heterochronic gene lin- 4 encodes small RNAs with antisense complementarity to lin-14. Cell 75(5), 843-854 (1993).

2 Croce CM: Causes and consequences of microRNA dysregulation in cancer. Nat. Rev. Genet. 10(10), 704-714 (2009).

3 Calin GA, Dumitru CD, Shimizu M et al: Frequent deletions and down-regulation of micro-RNA genes miR15 and miR16 at $13 \mathrm{q} 14$ in chronic lymphocytic leukemia. Proc. Natl Acad. Sci. USA 99(24), 15524-15529 (2002).

4 Fabbri M, Garzon R, Cimmino A et al.: MicroRNA-29 family reverts aberrant methylation in lung cancer by targeting DNA methyltransferases 3A and 3B. Proc. Natl Acad. Sci. USA 104(40), 15805-15810 (2007).

5 Jopling CL, Yi M, Lancaster AM, Lemon SM, Sarnow P: Modulation of hepatitis $\mathrm{C}$ virus RNA abundance by a liver-specific MicroRNA. Science 309(5740), 1577-1581 (2005).

6 Wang S, Aurora AB, Johnson BA et al.: The endothelial-specific microRNA miR-126 governs vascular integrity and angiogenesis. Dev. Cell 15(2), 261-271 (2008).

7 Liu CG, Spizzo R, Calin GA, Croce CM: Expression profiling of microRNA using oligo DNA arrays. Methods 44(1), 22-30 (2008).

8 Jiang J, Lee EJ, Gusev Y, Schmittgen TD: Real-time expression profiling of microRNA precursors in human cancer cell lines. Nucleic Acids Res. 33(17), 5394-5403 (2005).

9 Nygaard S, Jacobsen A, Lindow M et al.: Identification and analysis of miRNAs in human breast cancer and teratoma samples using deep sequencing. BMC Med. Genomics 2, 35 (2009).

10 Meng F, Henson R, Wehbe-Janek H, Ghoshal K, Jacob ST, Patel T: MicroRNA-21 regulates expression of the PTEN tumor suppressor gene in human hepatocellular cancer. Gastroenterology 133(2), 647-658 (2007).
11 Chan JA, Krichevsky AM, Kosik KS: MicroRNA-21 is an antiapoptotic factor in human glioblastoma cells. Cancer Res. 65(14), 6029-6033 (2005).

12 Frankel LB, Christoffersen NR, Jacobsen A, Lindow M, Krogh A, Lund AH: Programmed cell death 4 (PDCD4) is an important functional target of the microRNA miR-21 in breast cancer cells. J. Biol. Chem. 283(2), 1026-1033 (2008).

13 Ribas J, Ni X, Haffner M et al.: miR-21: an androgen receptor-regulated microRNA that promotes hormone-dependent and hormone-independent prostate cancer growth. Cancer Res. 69(18), 7165-7169 (2009).

14 Ma L, Young J, Prabhala H et al.: MiR-9, a MYC/MYCN-activated microRNA, regulates E-cadherin and cancer metastasis. Nat. Cell Biol. 12(3), 247-256 (2010).

15 Lee YS, Dutta A: The tumor suppressor microRNA let-7 represses the $H M G A 2$ oncogene. Genes Dev. 21(9), 1025-1030 (2007).

16 Johnson SM, Grosshans H, Shingara J et al.: RAS is regulated by the let-7 microRNA family. Cell 120(5), 635-647 (2005).

17 Yanaihara N, Caplen N, Bowman E et al.: Unique microRNA molecular profiles in lung cancer diagnosis and prognosis. Cancer Cell 9(3), 189-198 (2006).

18 Landi MT, Zhao Y, Rotunno M et al: MicroRNA expression differentiates histology and predicts survival of lung cancer. Clin. Cancer Res. 16(2), 430-441 (2010).

19 Ji J, Shi J, Budhu A et al.: MicroRNA expression, survival, and response to interferon in liver cancer. N. Engl. J. Med. 361(15), 1437-1447 (2009).

$20 \mathrm{Hu}$ X, Schwarz JK, Lewis JS et al: A microRNA expression signature for cervical cancer prognosis. Cancer Res. 70 (4), 1441-1448 (2010).
21 Lawrie CH, Gal S, Dunlop HM et al: : Detection of elevated levels of tumourassociated microRNAs in serum of patients with diffuse large B-cell lymphoma. Br. J. Haematol. 141(5), 672-675 (2008).

22 Haussecker D, Kay MA: miR-122 continues to blaze the trail for microRNA therapeutics. Mol. Ther. 18(2), 240-242 (2010).

23 Kota J, Chivukula RR, O'Donnell KA et al.: Therapeutic microRNA delivery suppresses tumorigenesis in a murine liver cancer model. Cell 137(6), 1005-1017 (2009).

24 Hunter MP, Ismail N, Zhang X et al.: Detection of microRNA expression in human peripheral blood microvesicles. PLoS One 3(11), E3694 (2008).

25 Mitchell PS, Parkin RK, Kroh EM et al: Circulating microRNAs as stable blood-based markers for cancer detection. Proc. Natl Acad. Sci. USA 105(30), 10513-10518 (2008).

26 Huang Z, Huang D, Ni S, Peng Z, Sheng W, Du X: Plasma microRNAs are promising novel biomarkers for early detection of colorectal cancer. Int. J. Cancer (2009) (Epub ahead of print).

27 Resnick KE, Alder H, Hagan JP, Richardson DL, Croce CM, Cohn DE: The detection of differentially expressed microRNAs from the serum of ovarian cancer patients using a novel real-time PCR platform. Gynecol. Oncol. 112(1), 55-59 (2009).

28 Calin GA, Liu CG, Ferracin M et al.: Ultraconserved regions encoding ncRNAs are altered in human leukemias and carcinomas. Cancer Cell 12(3), 215-229 (2007).

29 Shen J, Dicioccio R, Odunsi K, Lele SB, Zhao H: Novel genetic variants in miR-191 gene and familial ovarian cancer. BMC Cancer 10(1), 47 (2010).

30 Chin LJ, Ratner E, Leng S et al.: A SNP in a let-7 microRNA complementary site in the $K R A S 3^{\prime}$ untranslated region increases non-small cell lung cancer risk. Cancer Res. 68(20), 8535-8540 (2008). 